\title{
A escolarização das pessoas com deficiência no Brasil: atendimento, atraso e progressão no ensino fundamental segundo o Censo 2000
}

\author{
Tiago Henrique P. M. França* \\ Eduardo L. G. Rios-Neto**
}

\begin{abstract}
O presente artigo tem por objetivo evidenciar a implicação das deficiências sobre o atendimento, o atraso e a progressão escolar no ensino fundamental. Para tal, é utilizada a modelagem estatística logística binária. Após apresentação dos diferentes conceitos de deficiência, por meio do Censo 2000, transcorre-se a análise dos quesitos pretendidos. A progressão escolar é pesquisada por meio da medida nomeada probabilidade de progressão por série (PPS), dos três pontos de maior relevância no desenvolvimento do ensino fundamental. Os resultados indicam grande disparidade entre as deficiências na determinação dos elementos investigados. Em geral, todas as condições se mostram como fatores que desfavorecem o desenvolvimento na carreira escolar. Porém, a implicação das deficiências sobre as PPS se reduz com o avanço no ensino fundamental, sendo também menos significativa a cada etapa sequente. Entre os quesitos analisados, o atraso escolar demonstrou sofrer relevante variação, devido ao controle por fatores de natureza socioeconômica. No mais, este trabalho contém resultados e aponta contributos para o desenvolvimento científico dessa área de estudo.
\end{abstract}

Palavras-chave: Deficiência. Atendimento escolar. Atraso escolar. Probabilidade de progressão por série.

\section{Introdução}

A educação básica é um direito dos cidadãos e um dever do Estado, a ser concretizado pela iniciativa das famílias ou individual. O ensino fundamental é legalmente obrigatório e universal desde 1996. Tal universalização compreende atingir toda e qualquer criança em idade escolar e demais indivíduos que desejarem ingressar ou retomar aos estudos.

A universalização encontra diversos desafios para a sua efetivação. A Unesco indica que minorias sociais sofrem distintas restrições no acesso à educação. Essa mesma organização, ao monitorar o atendimento e o atraso escolar no Brasil referente a 2000 (UNESCO, 2008), verificou redução no atendimento de algumas minorias sociais: minorias étnicas; pessoas "vivendo em circunstâncias difíceis"; e pessoas do sexo feminino.

O presente trabalho propõe-se a analisar a escolarização de outra minoria: os deficientes. Precisamente, o estudo objetiva evidenciar de forma quantitativa, segundo os dados do Censo Demográfico de 2000, a relação entre as deficiências e o atendimento, o atraso e a progressão escolar no ensino fundamental. Orientado sob a hipótese de

\footnotetext{
* Sociólogo, mestre em Demografia pelo Cedeplar/UFMG, doutorando em Sociologia pela Universidade de Coimbra, Portugal.

${ }^{* *} \mathrm{PhD}$ em Demografia pela University of California at Berkeley, EUA, professor titular e chefe do departamento de Demografia do Cedeplar/UFMG.
} 
que as deficiências têm implicações próprias sobre os quesitos analisados, a investigação também explora como se desenvolve parte da carreira escolar dos deficientes no ensino fundamental, quando esses se encontram inseridos no sistema de ensino.

\section{Deficiências em definições e registro no Censo 2000}

O campo do conhecimento dedicado ao estudo das deficiências está internacionalmente estabelecido, sendo denominado de Disability Studies. São dois os principais paradigmas concorrentes nesse campo - os modelos médico e social -, que possuem definições próprias de deficiência e, consequentemente, orientações para o seu tratamento clínico e suas implicações na sociedade.

O modelo médico compreende a deficiência como uma condição de saúde, caracterizada por ocorrência de lesão no corpo, causada principalmente por doença que incapacita parcial ou integralmente o indivíduo para a execução de funções próprias da estrutura lesionada (DINIZ, 2007). O desenvolvimento desse modelo ocorreu pari passu ao avanço da medicina. Os tratamentos dados aos deficientes, de acordo com os preceitos desse modelo, são regidos pela chamada Ideologia da Normalização (ARANHA, 2001). Formalizado a partir da segunda metade do século $X X$, esse pensamento pressupõe a existência de uma função normal das atividades humanas e desvios que se distanciam da normalidade. A partir de então, promover à estrutura corporal lesionada uma funcionalidade mais próxima do normal quanto possível passou a ser o objetivo central do tratamento oferecido aos deficientes.

A lógica empregada por tal modelo tem a presença de deficiência como fator que levaria à incapacidade, sendo que ambas (deficiência e incapacidade) implicariam desvantagem social (handicap). A deficiência seria a causa tanto da incapacidade quanto das desvantagens vividas por quem a possui. Nessa perspectiva, a desvantagem social é fundamentalmente individual, sendo esse o principal ponto de crítica do modelo médico pelos teóricos do modelo social (DINIZ, 2007).

Por sua vez, advindo dos movimentos sociais dos deficientes ingleses na década de 1970, o modelo social compreende a deficiência como um estilo de vida imposto aos indivíduos que possuem um corpo com lesão (UPIAS, 1975). Estilo de vida comumente estigmatizado, tido como incapacitante e marginalizado socialmente. Desse ponto de vista, a deficiência não está no corpo. Ela ocorre quando um indivíduo possuidor de um corpo com lesão é impedido de exercer sua liberdade, principalmente um ser privado de participar da vida social.

Para as elaborações que compactuam com o modelo social da deficiência, as intervenções que buscam habilitar o deficiente para execução de tarefas são bem-vindas, mas não são suficientes. Para deixar de incapacitar aqueles que possuem corpo lesado, é necessário que a sociedade passe por uma reestruturação, promovendo a equidade das oportunidades sociais. Essa visão inaugura um novo paradigma da relação entre deficientes e sociedade, que distingue integração de inclusão (ARANHA, 2001), em que a primeira (integração) estaria focada no preparo do sujeito, seu corpo e habilidades para a vida social, enquanto a segunda (inclusão) estende-se para além do indivíduo, na intervenção na sociedade para propiciar a participação das pessoas com deficiência.

No âmbito educacional, como tendência inaugurada ainda no Brasil imperial, o desenvolvimento da educação especial se deu por meio da fundação de institutos especializados na educação de deficientes, com efeito para os cegos e os surdos (LANNA JR., 2010). Entretanto, sob o paradigma da inclusão, ocorreram as principais mudanças na educação das pessoas com deficiência na história recente do Brasil. Nessa perspectiva, a principal iniciativa para a chamada educação especial encontra-se na inserção do aluno com deficiência em classes normais de escolas regulares. Garantida pela Política Nacional de Educação Especial publicada em 1994, a princípio apenas para indivíduos que conseguirem acompanhar o ritmo dos demais alunos, 
a educação especial inclusiva tornou-se, a partir de 1999, oficialmente reconhecida como complementar à educação regular universal, devendo contemplar todos os níveis e modalidades de ensino (MEC, 2008).

Mesmo contando com algum otimismo, políticas de educação especial e suas tendências inclusivas crescentes podem não ser suficientes para garantir aos deficientes o acesso à educação. As medidas para promoção da educação usualmente restringem-se ao ambiente escolar, sejam estas de âmbito físico e instrumental ou voltadas para práticas educativas. Contudo, a investigação do atendimento educacional e do desenvolvimento da carreira escolar dessa parcela da população deve considerar, também, aqueles que se encontram fora da escola, o que requer um modo de avaliação externo, por meio de dados não escolares, sendo o Censo Demográfico, portanto, uma fonte de grande valia devido à sua abrangência.

As deficiências como mensuradas no Censo 2000 fogem do dualismo fundamentado na oposição dos modelos de deficiência, não se focando estritamente nem na participação social nem no corpo, mas, sobretudo, nas limitações individuais. Diferentemente dos censos anteriores, o de 2000 se concentra nas capacidades funcionais dos entrevistados, além de inquirir pontualmente sobre determinadas condições do corpo (Quadro 1). Segundo Mont (2007), tal modo de mensuração vai

QUADRO 1

Variáveis do Censo 2000 referentes às deficiências

\begin{tabular}{|c|c|c|}
\hline Título & Descrição & Categorias \\
\hline $\begin{array}{l}\text { Problema mental } \\
\text { permanente }\end{array}$ & $\begin{array}{l}\text { A deficiência mental é definida pelo retardamento } \\
\text { mental resultante de lesão ou síndrome irreversível, } \\
\text { que se caracteriza por dificuldades ou limitações } \\
\text { intelectuais associadas a duas ou mais habilidades } \\
\text { adaptativas, tais como: comunicação, cuidado } \\
\text { pessoal, autodeterminação, cuidados com saúde e } \\
\text { segurança, aprendizagem, lazer, trabalho etc. } \\
\text { Existência de deficiência mental. }\end{array}$ & $\begin{array}{l}1 \text { - Sim } \\
2 \text { - Não } \\
9 \text { - Ignorado }\end{array}$ \\
\hline $\begin{array}{l}\text { Capacidade de } \\
\text { enxergar }\end{array}$ & $\begin{array}{l}\text { Autoavaliação da capacidade de enxergar. } \\
\text { Nota: caso a pessoa usasse óculos ou lentes de } \\
\text { contacto, a avaliação foi feita enquanto os estivesse } \\
\text { usando. }\end{array}$ & $\begin{array}{l}1 \text { - Incapaz } \\
2 \text { - Grande dificuldade permanente } \\
3 \text { - Alguma dificuldade permanente } \\
4 \text { - Nenhuma dificuldade } \\
9 \text { - Ignorado }\end{array}$ \\
\hline $\begin{array}{l}\text { Capacidade de } \\
\text { ouvir }\end{array}$ & $\begin{array}{l}\text { Autoavaliação da capacidade de ouvir. } \\
\text { Nota: caso a pessoa usasse aparelho auditivo, a } \\
\text { avaliação foi feita enquanto o estivesse usando. }\end{array}$ & $\begin{array}{l}1 \text { - Incapaz } \\
2 \text { - Grande dificuldade permanente } \\
3 \text { - Alguma dificuldade permanente } \\
4 \text { - Nenhuma dificuldade } \\
9 \text { - Ignorado }\end{array}$ \\
\hline $\begin{array}{l}\text { Capacidade de } \\
\text { caminhar/subir } \\
\text { escadas }\end{array}$ & $\begin{array}{l}\text { Autoavaliação da capacidade de caminhar/subir } \\
\text { escadas. } \\
\text { Nota: caso a pessoa usasse prótese, bengala ou } \\
\text { aparelho auxiliar, a avaliação foi feita enquanto os } \\
\text { estivesse usando. }\end{array}$ & $\begin{array}{l}1 \text { - Incapaz } \\
2 \text { - Grande dificuldade permanente } \\
3 \text { - Alguma dificuldade permanente } \\
4 \text { - Nenhuma dificuldade } \\
9 \text { - Ignorado }\end{array}$ \\
\hline Deficiências & Tipo de deficiência física & $\begin{array}{l}1 \text { - Paralisia permanente total (possui } \\
\text { paralisia dos quatro membros ) } \\
2 \text { - Paralisia permanente das pernas } \\
3 \text { - Paralisia permanente de um dos } \\
\text { lados do corpo } \\
4 \text { - Falta de perna, braço, mão, pé ou } \\
\text { dedo polegar (também foi considerada } \\
\text { neste caso a pessoa que declarou } \\
\text { perda de parte de um braço ou perna) } \\
5 \text { - Nenhuma das enumeradas } \\
9 \text { - Ignorado }\end{array}$ \\
\hline
\end{tabular}

Fonte: IBGE. Censo Demográfico 2000. 
ao encontro dos objetivos de monitorar o nível de funcionalidade de uma população e estimar a provisão de serviços e outras demandas sociais, assim como pode contribuir para avaliar a equalização de oportunidades vivenciadas por determinada sociedade, o que a priori aponta para uma adequação dos dados para a presente investigação.

No Censo 2000 , são cinco variáveis inquiridas e três formas de respostas que abarcam as condições físicas e capacidades funcionais dos entrevistados. $\mathrm{Na}$ ordem da entrevista (IBGE 2000), a primeira questão é relacionada à saúde mental, o registro de problema mental permanente. A seguir três variáveis avaliam a capacidade funcional declarada em enxergar, ouvir e subir escada/ caminhar, que, juntas, representam o maior avanço entre os censos demográficos brasileiros no registro de deficiências (NERI, 2003). Por fim, o indivíduo é inquirido sobre a presença de alguma paralisia ou perda de membros, segundo uma lista: paralisia permanente total; paralisia permanente das pernas; paralisia permanente de um dos lados do corpo; e falta de perna, braço, mão, pé ou dedo polegar. Se considerada a prevalência das dificuldades permanentes em enxergar, ouvir e subir escada/caminhar como deficiência, aliadas às paralisias, falta de membro e problema mental, o percentual de deficientes captados em 2000 pelo Censo é $14,5 \%$ do total populacional.

Contudo, o presente estudo excluiu de suas análises a variável em que é avaliada a capacidade de caminhar/subir escadas em primazia da variável de paralisias. As variáveis tendem a ter implicações correlatas que impediriam uma boa aplicação do método de investigação utilizado. Portanto, são 11 as categorias de interesse nas análises realizadas.

\section{Metodologia}

A partir das elaborações como a do Capital Humano de Becker (1964), muitos estudos foram realizados com o intuito de decifrar os fatores que promovem as oportunidades educacionais. Nessa perspectiva, deve-se destacar a elaboração teórica intitulada Função de Produção Educacional FPE, operacionalizada por Todd e Wolpin (2003). Fundamentalmente, segundo essa teoria, a educação, tomada como acúmulo de conhecimento, é o resultado de um processo produtivo cujos insumos advêm de diferentes fontes: a escola, a família e a comunidade. Hanushek (2002) sumariza os insumos de maior impacto da FPE entre escolares (educação e experiência do professor, tamanho da turma, gasto por estudante, gasto com professores, entre outros) e familiares (educação da mãe e do pai, renda, atitudes e expectativas, etc.).

Investigações que utilizam a FPE tendem buscar fatores mensuráveis que aumentariam os resultados educacionais. No presente estudo, o interesse se concentra na investigação de características do indivíduo que agiriam de forma contrária: condições de saúde caracterizadas pela presença de deficiências. Portanto, configura objetivo deste trabalho elucidar a relação entre as deficiências e os resultados educacionais (atendimento, atraso e progressão escolar).

Robert Mare (1980), por sua vez, dedicou-se a estudar a interferência do background social e familiar dos alunos na probabilidade de prosseguirem em determinados pontos da carreira escolar. Segundo seus resultados, duas hipóteses foram postuladas: a implicação dos diferentes backgrounds sociais dos alunos diminui à medida que se avança na carreira escolar (MARE, 1980); quando há expansão do ensino entre coortes, reduz-se o impacto do background social sobre a escolarização (MARE, 1981). ${ }^{1}$ Quanto às deficiências, as diferenças do corpo agiriam como as diferenças na origem social? De forma análoga à primeira hipótese de Mare, a presente investigação trabalha a suposição de que a implicação das deficiências se difere em pontos distintos da carreira escolar, configurando uma tendência decrescente

\footnotetext{
1 Para conhecer melhor as hipóteses de Mare, discussões teóricas advindas dessas, assim como a verificação das hipóteses aplicadas à realidade brasileira, é indicado o trabalho de Guimarães (2010).
} 
da implicação das deficiências sobre a progressão escolar.

O método empregado para efetivação da investigação é a análise de regressões logísticas. Os Modelos Logísticos Binários são caracterizados por identificar e mensurar a significância e a intensidade da relação entre uma ou mais variáveis explicativas sobre uma variável resposta dicotômica. No caso, as variáveis respostas serão: frequenta a escola (ou não); está atrasado (ou não); e progrediu (ou não) nos pontos específicos da carreira estudantil (a conclusão do primeiro, quinto e nono anos de estudo notada por $e_{0}, e_{4}$ e $e_{8}$, respectivamente). Hosmer e Lemeshow' (1989) definem o Modelo Logístico Múltiplo em:

$$
\pi(x)=\frac{e^{\beta \mathrm{x}}}{\left(1+e^{\beta \mathrm{x}}\right)}
$$

onde: $\pi(x)$ é a probabilidade condicional do sucesso do evento dado às condições denotadas pelo conjunto de características $\mathrm{x}$; $\beta \mathrm{x}$ é o somatório das multiplicações dos coeficientes estimados $(\beta)$ pelas variáveis explicativas $(x)$.

Resultante do ajuste do modelo têmse os coeficientes estimados e a chance de ocorrência do evento associada às variáveis explicativas. Nesta investigação, as variáveis explicativas selecionadas foram divididas em dois grupos. O primeiro referese àquelas de interesse que constam em todos os modelos ajustados: idade; sexo; deficiência mental declarada; avaliação da capacidade de enxergar; avaliação da capacidade de ouvir; e deficiência física declarada. Sobre esse grupo, e estritamente circunscritas às variáveis de deficiência, transcorrem as análises estatísticas dos quesitos escolares. Nos modelos ajustados, as categorias de referência de tais variáveis condizem às suas negativas, tanto em sua não ocorrência (nas variáveis de deficiências mental e físicas), quanto na falta de dificuldades permanentes (nas variáveis de capacidade). Ou seja, as análises contrastam os quesitos educacionais de quem possui declarada cada uma das deficiências com aqueles que declararam não portar deficiência alguma.
O segundo grupo de variáveis explicativas, que alterna em sua participação na modelagem estatística, tem por função compor o controle dos efeitos do contexto socioeconômico na análise pretendida. Seguindo a tradição dos estudos sobre a eficácia escolar iniciados por Coleman (1966), que evidencia a importância dos fatores extraescolares nos resultados educacionais, diversos trabalhos buscaram utilizar essa consagrada abordagem. Referenciando-se em estudos aplicados ao caso brasileiro, como, por exemplo, o de Macedo (2004), que investiga os fatores associados ao rendimento escolar no ensino fundamental, e tendo em vista as limitações oferecidas pelos dados do Censo Demográfico 2000, foi realizada a seleção de variáveis para elaboração do contexto socioeconômico. A seleção pretende abarcar elementos da composição da demanda individual por ensino, segundo fatores do indivíduo, de sua família, de seu domicílio e comunidade. Foram selecionadas as seguintes variáveis para essa função: cor; indicação de família monoparental; escolaridade do chefe da família; densidade de moradores por dormitório; indicativo de água encanada, esgoto encanado, eletricidade, coleta de lixo e microcomputador; localidade (rural e urbana); indicativo de estar em região metropolitana; e macrorregião do país. No Anexo I, encontram-se os modelos estimados utilizados nas análises.

No método empregado, a significância de um parâmetro indica a possibilidade de a relação estimada entre uma variável explicativa (e seus parâmetros) e a variável resposta ocorrer de fato, segundo a variabilidade existente nos dados. Logo, a significância dos parâmetros estimados sugere se as tendências presentes nos dados são robustas após o ajuste do modelo. Inversamente proporcional à significância, o P-valor é um dos indicadores mais comuns nessa análise. Diz-se, então, que quanto maior o P-valor, menor a significância do parâmetro. Nas Ciências Sociais, é comumente adotado o valor de 0,05 para o P-valor como critério entre valores passíveis ou não de interpretação. Os modelos utilizados na análise desta investigação indicaram alta significância 
(P-valor inferior a 0,01$)^{2}$ dos parâmetros relacionados às variáveis de deficiência nos ajustes, referentes ao atendimento e atraso escolar. Por sua vez, os modelos utilizados no estudo da progressão escolar possuem variação na significância, o que será devidamente incorporada na análise.

\section{Resultados}

\section{Atendimento escolar}

A taxa de atendimento é definida pela frequência relativa à escola na semana de referência do Censo. Nas palavras de Riani e Golgher (2004, p. 114-115):

ela capta a proporção de uma população em determinada faixa etária que frequenta a escola, podendo avaliar a capacidade do sistema de ensino de manter as crianças e adolescentes nas escolas.

No nível do indivíduo, o atendimento é indicado pela declaração de estar frequentando (ou não) a escola nos dados da amostra do Censo 2000. Os recortes aplicados na análise do atendimento foram realizados sob os quesitos da idade (7 a 17 anos completos) e tipo de domicílio (residir em domicílio particular permanente), uma vez que não é inquirida grande parte das variáveis domiciliares para aqueles que vivem em outras condições de habitação.

Como ilustrado no Gráfico 1, a taxa de atendimento varia entre os grupos populacionais caracterizados pela presença de deficiências. O estudo das taxas não é suficiente para compreender como as deficiências se relacionam ao atendimento no nível do indivíduo, uma vez que as taxas, mesmo específicas por categorias de deficiências, podem resultar de fatores diversos que atuam de forma concomitante, relativos sobretudo à origem social dos indivíduos.

Investigação mais precisa foi realizada por meio do ajuste de modelos estatísticos. Quando se comparam os coeficientes das variáveis de deficiência na ausência e presença de controle por variáveis socioeconômicas (modelos I-A e I-B, respectivamente), são percebidas poucas alterações (Gráfico 2). Essa constatação possivelmente indica que as variáveis de deficiência e as socioeconômicas não coincidem em suas implicações sobre o atendimento escolar. Os coeficientes que sofrem maior variação em termos relativos, em função da inclusão dos fatores socioeconômicos, são das categorias alguma dificuldade em ouvir e a falta de membro. Ambas as condições de saúde, que já possuem coeficientes baixos, em relação à média das demais categorias, os têm ainda mais reduzidos na presença de fatores explicativos de natureza socioeconômica, o que pode indicar ocorrência de maior suscetibilidade dessas deficiências à presença de barreiras (familiares e econômicas) ao atendimento escolar e/ou indicaria correlação entre a prevalência dessas condições e contextos socioeconômicos desfavoráveis ao atendimento escolar. As demais categorias obtiveram uma variação inferior a $21 \%$ em seus coeficientes, sendo que algumas hipóteses podem ser formuladas para problematizar essa questão. ${ }^{3}$

Para compreender o quanto as deficiências implicam na redução do atendimento escolar, um breve exercício foi realizado. A partir dos valores modais de cada variável ${ }^{4}$ do bloco socioeconômico, foi definido um perfil chamado de perfil modal. ${ }^{5}$ Utilizando

\footnotetext{
2 O mesmo nível de significância foi obtido no teste Hosmer-Lemeshow de adequação aplicado a todos os modelos ajustados. Para informação pormenorizada acerca da significância e outros aspectos dos modelos ajustados, assim como interação entre as variáveis de deficiência e idade e sexo, consultar França (2010).

$3 \mathrm{O}$ investimento no aprontamento do indivíduo para o ingresso escolar é ineficaz em determinadas condições de saúde; os recursos familiares não atingem a capacidade das escolas de prover atendimento aos deficientes; o poder de investimento das famílias no aprontamento do indivíduo para o ingresso escolar é baixo; não há carência na oferta do ensino fundamental por parte das escolas, criando uma independência entre o atendimento e o poder econômico das famílias. ${ }^{4}$ Com exceção das variáveis de valor não categóricas. A idade foi definida a partir do ponto médio de sua distribuição. Os anos de estudo do chefe da família, assim como a densidade de moradores por dormitório, foram referenciados pelo valor de suas medianas.

5 Sexo masculino, 12 anos de idade, branco, em família biparental cujo chefe possui quatro anos de estudos completos. Morador de região urbana não metropolitana do Sudeste do país, em domicílio com água canalizada, eletricidade, esgoto, serviço de limpeza e sem microcomputador e densidade de dois moradores por dormitório.
} 
GRÁFICO 1

Taxas de atendimento de indivíduos de 7 a 17 anos, por categoria de deficiência Brasil - 2000

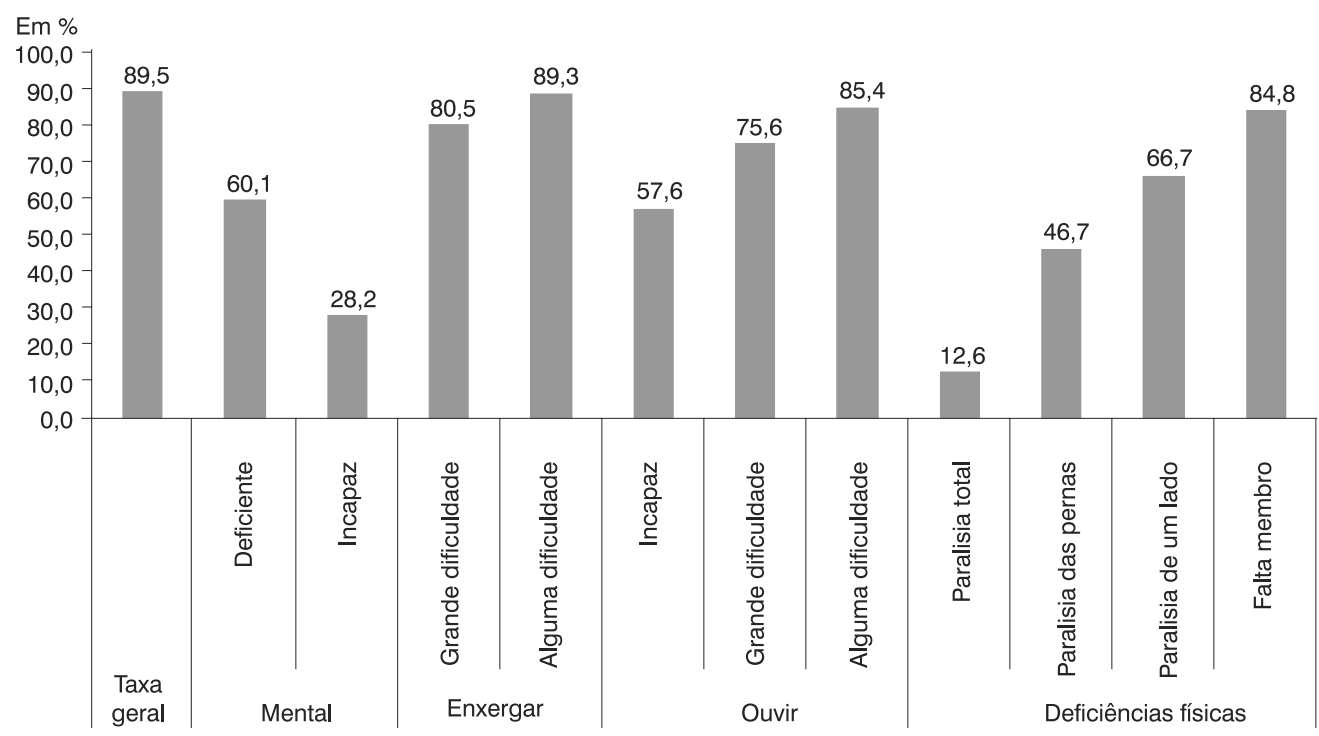

Fonte: IBGE. Censo Demográfico 2000.

GRÁFICO 2

Coeficientes das categorias de deficiência dos modelos do atendimento I-A e I-B para indivíduos de 7 a 17 anos Brasil - 2000

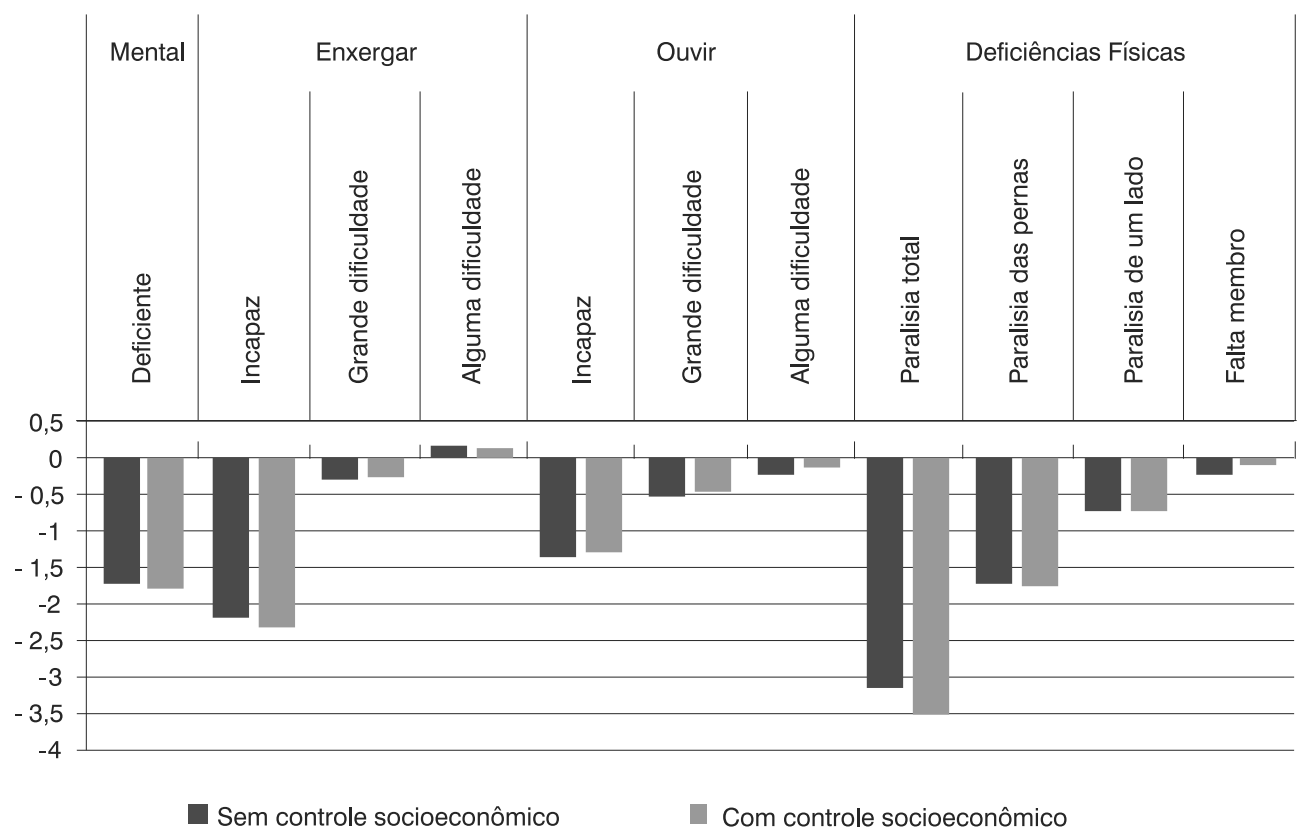

Fonte: IBGE. Censo Demográfico 2000. 
os coeficientes da regressão do modelo I-B, estimou-se a probabilidade predita para um indivíduo no perfil modal estar frequentando a escola. Em seguida, os coeficientes das deficiências foram adicionados ao cálculo, um por vez, gerando novas probabilidades (Tabela 1).

O modelo prediz, para o perfil modal, a probabilidade de 0,78 de atendimento escolar. Os indivíduos com paralisia total têm apenas $12 \%$ de probabilidade de estar na escola em relação a alguém que não possui deficiência alguma. As demais deficiências que reduziram a probabilidade de atendimento para menos de sua metade foram a incapacidade de enxergar, a deficiência mental e a paralisia das pernas. Por sua vez, algumas categorias possuem pelo menos $90 \%$ da probabilidade do perfil modal: grande dificuldade e alguma dificuldade de enxergar, alguma dificuldade de ouvir e falta de membro (braço, perna, mão, pé ou dedo polegar).

Contra ao intuitivo, possuir alguma dificuldade permanente de enxergar aumen- taria a chance de ser atendido pela escola. Porém, é possível que os coeficientes positivos dessa categoria estejam refletindo a importância da escola na identificação dessa condição na visão.

\section{Atraso escolar}

O atraso escolar foi elaborado a partir do cruzamento entre a idade e os anos completos de estudo dos indivíduos. É notado atraso para o indivíduo que está defasado em dois ou mais anos da correspondência idade-série regular. Essa variável capta o atraso que ocorre dos nove anos de idade em diante, portanto, toda a análise que se segue deste elemento está circunscrita dos 9 aos 17 anos de idade e, como no atendimento, em residentes de domicílios particulares permanentes.

Nas análises desse quesito foram considerados somente os indivíduos que estavam frequentando a escola segundo o período de referência do censo, ou seja, o atraso condicional dado o atendimento escolar. ${ }^{6}$

TABELA 1

Probabilidades de atendimento preditas a partir do modelo I-B sobre o perfil modal (1), segundo categorias de deficiência

Brasil - 2000

\begin{tabular}{llcc}
\hline \multicolumn{1}{c}{ Deficiências } & Probabilidades & $\begin{array}{c}\text { Razão entre prob. deficiente } \\
\text { e prob. perfil modal }\end{array}$ \\
\hline Mental & Perfil Modal & 0,78 & - \\
\hline \multirow{3}{*}{ Enxergar } & Deficiente & 0,37 & 0,48 \\
& Incapaz & 0,25 & 0,33 \\
& Grande dificuldade & 0,73 & 0,93 \\
Ouvir & Alguma dificuldade & 0,80 & 1,03 \\
& Incapaz & 0,49 & 0,63 \\
& Grande dificuldade & 0,69 & 0,89 \\
\multirow{3}{*}{ Físicas } & Alguma dificuldade & 0,75 & 0,97 \\
& Paralisia total & 0,09 & 0,12 \\
& Paralisia das pernas & 0,37 & 0,48 \\
\hline
\end{tabular}

Fonte: IBGE. Censo Demográfico 2000.

(1) Sexo masculino, 12 anos de idade, branco, em família biparental cujo chefe possui quatro anos de estudos completos. Morador de região urbana não metropolitana do Sudeste do país, em domicílio com água canalizada, eletricidade, esgoto, serviço de limpeza e sem microcomputador e densidade de dois moradores por dormitório.

\footnotetext{
6 Conceitualmente, não frequentar a escola, seja por limitação de acesso ou mesmo por ter encerrado a carreira escolar antes dos 17 anos, poderia ser contabilizado como atraso caso essa condicionalidade não fosse aplicada. Dessa forma, evitar esses casos, circunscrevendo o atraso somente entre os estudantes, torna seu registro mais preciso. Por outro lado, a entrada tardia na escola não é possível de ser controlada, e invariavelmente será notada como atraso escolar para quem está estudando, o que preferencialmente seria mais bem classificado como ausência de atendimento.
} 
As taxas de atraso específicas por deficiência são, em todos os casos, superiores à taxa geral da população circunscrita nas idades investigadas. Em apenas dois grupos foram observados valores inferiores a $50 \%$ (alguma dificuldade de enxergar e falta de membros) e em seis categorias as taxas estão entre 60\% e 70\% (Gráfico 3).
Nos modelos II-A e II-B (Gráfico 4), à primeira vista, a variável relativa à audição tem destaque por atingir o mais alto dos valores, indicando que, entre os deficientes, os surdos são aqueles que, por essa condição, teriam maior chance de atrasar os estudos quando estão inseridos na escola. Assim como no estudo do atendimento,

\section{GRÁFICO 3}

Taxas de atraso escolar dos indivíduos de 9 a 17 anos, por categorias de deficiência Brasil - 2000

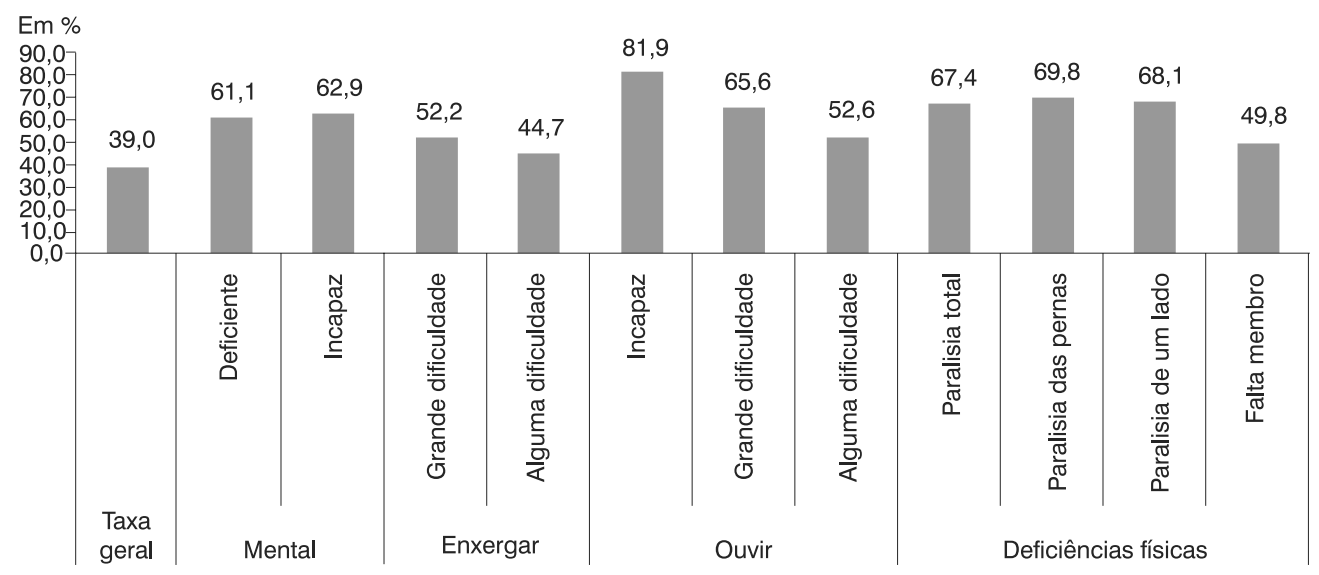

Fonte: IBGE. Censo Demográfico 2000.

GRÁFICO 4

Coeficientes das categorias de deficiência dos modelos de atraso escolar II-A e II-B, para indivíduos de 9 a 17 anos Brasil - 2000

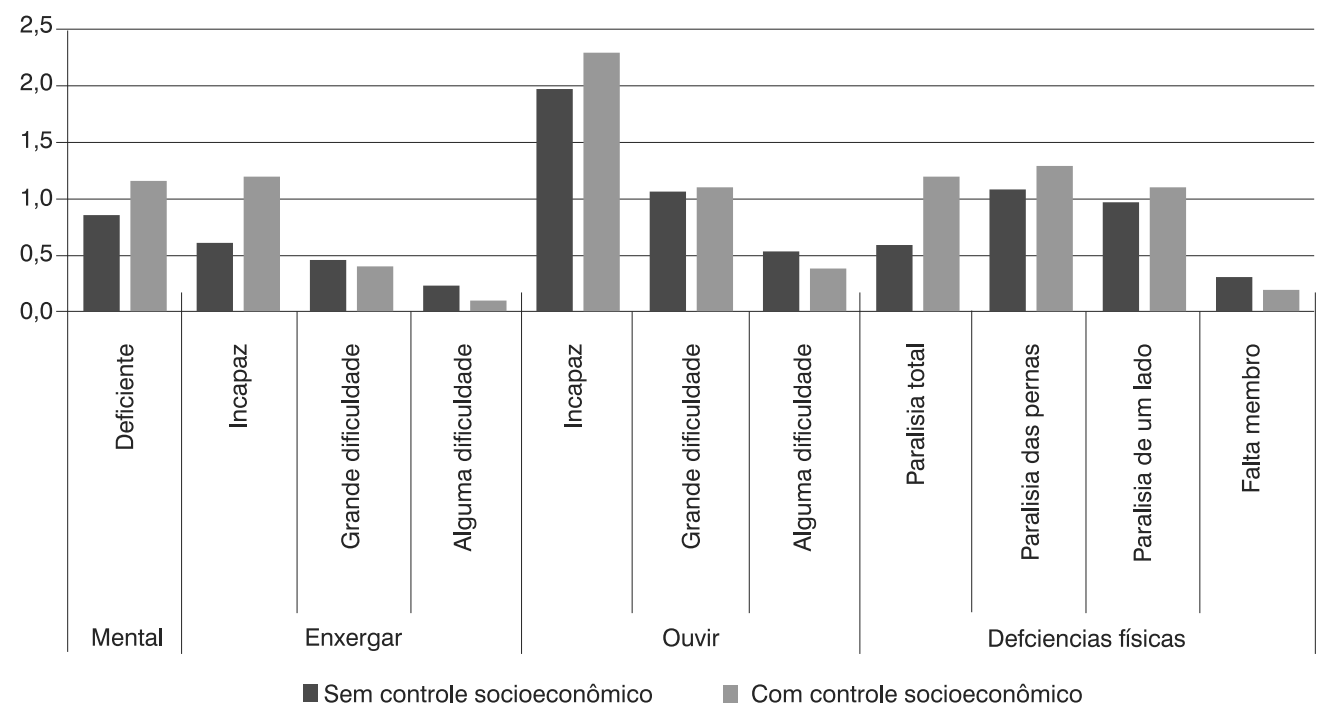

Fonte: IBGE. Censo Demográfico 2000. 
as deficiências que apresentaram menor implicação sobre a variável resposta são a falta de membro e alguma dificuldade em enxergar. Outra questão que merece destaque refere-se aos coeficientes das paralisias, que não seguem a mesma ordenação em valores daquela observada na modelagem do atendimento, expressando valores próximos uns dos outros. Essa nova ordenação é o primeiro indício de seletividade advinda do atendimento, uma vez que são esperados, em geral, resultados escolares inferiores para condições de saúde mais limitadoras como a paralisia total. A seletividade dessa natureza será analisada com maior atenção mais adiante.

Quando comparados os coeficientes das variáveis de deficiência e o controle pelo background socioeconômico (Gráficos 2 e 4), percebe-se que há maior variação nos coeficientes referentes ao atraso escolar, em relação aos vistos no atendimento. A implicação das deficiências sobre o atraso escolar sofre forte alteração devido à presença de fatores explicativos de origem socioeconômica em pelo menos cinco das 11 condições de saúde investigadas, variando em mais de $40 \%$ o valor de seus coeficientes (modelos II-A e II-B). São elas: alguma dificuldade e incapacidade de enxergar; alguma dificuldade em ouvir; paralisia total; e falta de membro.

Ao analisar as diferenças encontradas nos coeficientes advindas do controle socioeconômico na determinação do atraso (modelos II-A e II-B), nota-se, para algumas deficiências, redução do coeficiente, enquanto para outras ocorre o contrário. As deficiências menos impeditivas para o atendimento ${ }^{7}$ tiveram decréscimo de seus coeficientes quando controlados por fatores socioeconômicos, indicando que, em média, o background social em que esses sujeitos se encontram favorece o atraso escolar.

A maior parte das condições, porém, tem seus coeficientes aumentados quando há controle pelo background social, implicando favorecimento do aluno devido ao contexto em que vive, ao aumentar a chance de não se atrasar na carreira escolar. Entre as deficiências nessa situação, as três que obtiveram maior variação de seus coeficientes ${ }^{8}$ são as mesmas que demonstraram estar mais fortemente associadas à falta de atendimento escolar. Essa associação indica que, potencialmente, a já reduzida porção de indivíduos com deficiência que conseguem ingressar na escola se beneficia ou depende, em grande parte, de recursos outros (familiares, domiciliares e locais), para um desenvolvimento adequado da carreira escolar.

Apenas conhecer os coeficientes das variáveis de deficiência não é suficiente para saber o quanto cada deficiência colabora para o atraso escolar. Assim como para a análise do atendimento, para facilitar a interpretação da implicação das deficiências sobre o atraso escolar, foi realizado o exercício de atribuição de deficiência ao perfil modal, desta vez utilizando os coeficientes do modelo II-B. O resultado desse exercício (exposto na Tabela 2) indica que o modelo proposto prediz alta probabilidade de atraso para o perfil modal $(0,77)$, a qual pode ser maior em $2 \%$ a $26 \%$ em decorrência de uma única deficiência.

Seis deficiências apresentaram aumento entre $18 \%$ e $20 \%$ na probabilidade de atraso sobre o perfil modal. Isso sugere que, quanto ao atraso condicional dado por frequentar a escola, após o controle por atributos socioeconômicos, a implicação da maior parte das deficiências sobre o atraso está em um mesmo patamar, no que tange sua ocorrência. Diferindo desses casos, observa-se que a surdez apresenta o mais proeminente atraso, enquanto a falta de membro, a dificuldade de enxergar e alguma dificuldade em ouvir registram atrasos menos expressivos.

\section{Progressão escolar - a probabilidade de progressão por série}

A probabilidade de progressão por série - PPS, elaborada por Rios-Neto

\footnotetext{
${ }^{7}$ Alguma dificuldade de enxergar, falta de membro, alguma dificuldade em ouvir e grande dificuldade em enxergar, nesta ordem.

8 Paralisia total, cegueira e deficiência mental, nesta ordem.
} 
TABELA 2

Probabilidades de atraso escolar preditas a partir do modelo II-B sobre o perfil modal, segundo categorias de deficiência

Brasil - 2000

\begin{tabular}{llcc}
\hline \multicolumn{1}{c}{ Deficiências } & \multicolumn{1}{c}{ Categorias } & Probabilidade & $\begin{array}{c}\text { Razão entre prob. deficiente } \\
\text { e prob.perfil modal }\end{array}$ \\
\hline Mental & Perfil modal & 0,77 & - \\
\hline \multirow{3}{*}{ Enxergar } & Deficiente & 0,91 & 1,19 \\
& Incapaz & 0,92 & 1,19 \\
& Grande dificuldade & 0,83 & 1,08 \\
Ouvir & Alguma dificuldade & 0,78 & 1,02 \\
& Incapaz & 0,97 & 1,26 \\
& Grande dificuldade & 0,91 & 1,18 \\
\multirow{3}{*}{ Físicas } & Alguma dificuldade & 0,83 & 1,08 \\
& Paralisia total & 0,91 & 1,19 \\
& Paralisia das pernas & 0,92 & 1,20 \\
& Paralisia de um lado & 0,91 & 1,18 \\
& Falta de membro & 0,80 & 1,04 \\
\hline
\end{tabular}

Fonte: IBGE. Censo Demográfico 2000.

(2004), consiste na probabilidade de se alcançar $\mathrm{X}+1$ anos de estudo, uma vez que se possui $X$ anos de estudo completos, para determinada coorte em certo período. Além das probabilidades em si, essa técnica também permite estimar os anos de estudo de uma coorte, por meio da soma das consecutivas probabilidades. Em sua formalização, a PPS é descrita por:

$$
e_{i}=\frac{P_{i+1}}{P_{i}}
$$

onde: $e_{i}$ é a probabilidade de progressão da série $i$ para a série $i+1 ; P_{i+1}$ corresponde às pessoas na coorte que concluíram pelo menos a série $i+1$; e $P_{i}$ refere-se às pessoas na coorte que concluíram pelo menos a série $i$.

A contagem dos anos de estudo para a PPS é iniciada a partir do ingresso no ensino fundamental. É nomeada $e_{0}$ a probabilidade de se concluir o $1^{\circ}$ ano de estudo com sucesso, dado que se tenha zero anos de estudo, e $e_{1}$ a probabilidade de se concluir o 2 ano de estudo com sucesso, dado que se tenha o 1ำ ano concluído, e assim por diante. $O$ presente estudo se concentra em analisar as variações de apenas três probabilidades, $e_{0}, e_{4}$ e $e_{8}{ }^{9}$

Para a análise das PPS, os dados foram filtrados somente pela afirmativa de morar em domicílio particular permanente e ter entre 7 e 17 anos. Para $e_{4}$ e $e_{8}$, por suas próprias definições, também foram filtrados segundo a escolaridade (quatro ou mais, e oito ou mais anos de estudo, respectivamente).

Como esperado para a população geral, as PPS compõem uma tendência decrescente, ou seja, com o avanço na carreira escolar do ensino fundamental, reduz-se a probabilidade de progredir. No entanto, o mesmo não ocorre para todos os grupos populacionais demarcados pelas deficiências, como pode ser observado no Gráfico 5.10

As tendências da PPS dos deficientes apresentaram resultados divergentes da distribuição populacional geral. Nos grupos de menor restrição no atendimento, as PPS se aproximam do formato esperado

\footnotetext{
9 As probabilidades de se concluir com sucesso o 1 ㅇ e 5o anos do ensino fundamental e a transição do ensino fundamental para o ensino médio, concluindo o primeiro ano deste com sucesso. A escolha desses momentos da carreira escolar é consequência da exploração dos próprios dados do Censo 2000 realizada por Rios-Neto (2004). A entrada na educação básica e essas duas transições na carreira escolar são momentos em que se observam reduções nas probabilidades em relação às suas antecessoras e sucessoras, indicando que agem imprimindo seletividade à continuidade nos estudos.

10 Valores pontuais e acumulados encontram-se no Anexo II.
} 
Probabilidades de progressão por série de período, $e_{0}, e_{4} e e_{8}$, para indivíduos de 7 a 17 anos, por categoria de deficiência

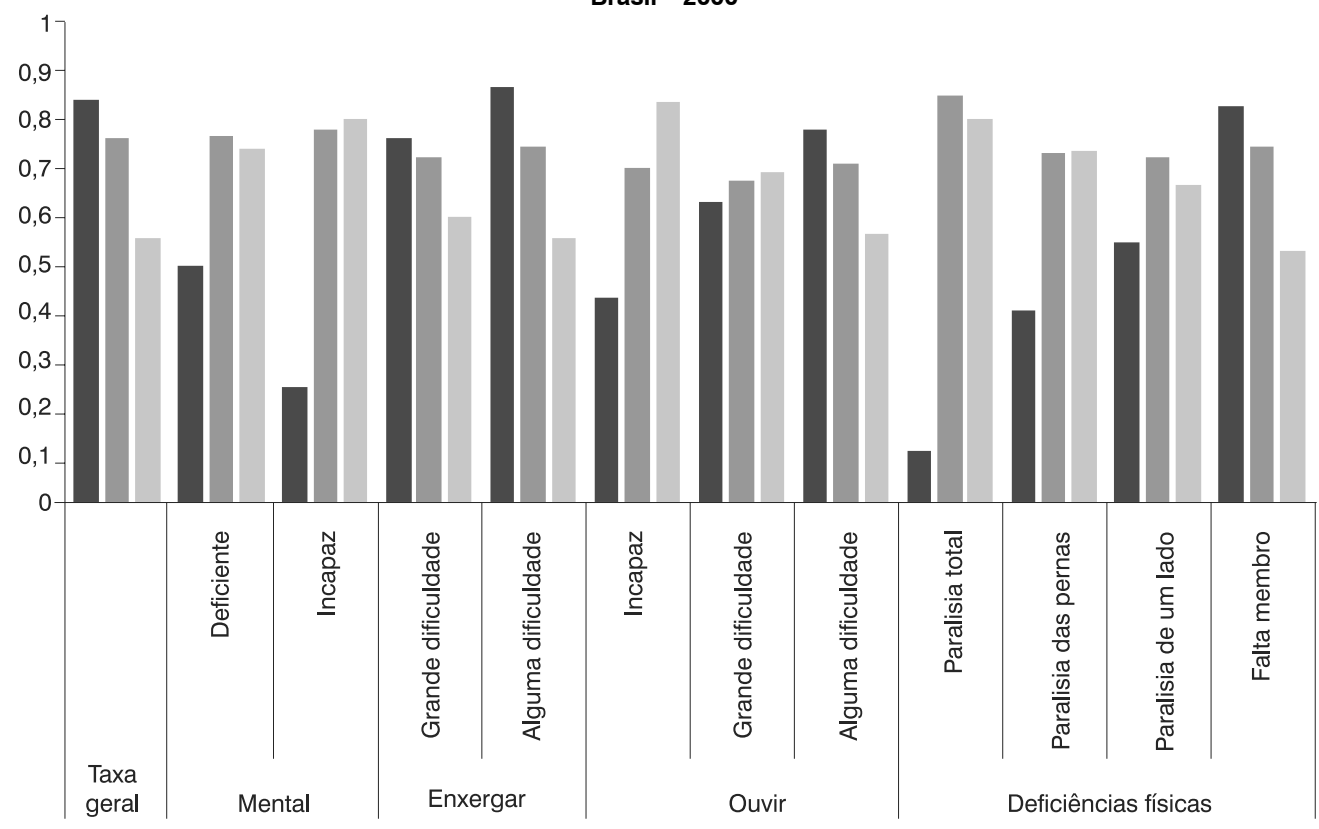

Fonte: IBGE. Censo Demográfico 2000.

para a população geral, ao passo que o contrário pode ser observado nos grupos de atendimento mais restrito. Ou seja, para esses, a probabilidade de concluir com sucesso o primeiro ano do ensino médio, dado que se concluiu o ensino fundamental, é maior do que a média populacional.

Em análise transversal como a realizada neste trabalho, Mare (1979) postulou que o impacto do background social dos alunos sobre a progressão nos níveis de ensino tende a reduzir à medida que se processe na carreira escolar. Ao analisar a significância dos fatores correspondentes a tal impacto, o autor conclui que "there is much more change in progression rates at the earliest schooling levels and both background and nonbackground sources of variability are greatest there" (MARE, 1979, p. 67). Assim, se consideradas as condições de saúde como fonte da variabilidade passível de explicação, as deficiências seguiriam a mesma tendência observada por Mare nos fatores socioeconômicos?
A Tabela 3 sumariza os resultados de interesse dos modelos, cujas variáveis explicativas são as PPS e o atendimento (modelos I-B, III-A, III-B e III-C) em significância e valores dos coeficientes. Em sua análise, deve-se ter em mente que os elementos pouco significativos podem indicar tanto a indiferença na implicação das categorias sobre a variável resposta, quanto a incapacidade do modelo de captar diferenciações, devido à baixa prevalência das deficiências quando empregados os recortes em $e_{4}$ e $e_{8}$. Há também a possibilidade de que ambos os fenômenos ocorram de forma conjugada, sendo que se selecione a mais apta e menor parte dos deficientes, ao ponto que sua deficiência seja indiferente à progressão. Os resultados estatisticamente mais consistentes são aqueles que se referem às deficiências mais frequentes nos dados: a deficiência mental e alguma dificuldade em enxergar.

Partindo dos resultados nas variáveis da visão e deficiências físicas, as categorias 
TABELA 3

Coeficientes e significância das variáveis de deficiência do modelo de atendimento I-B, e dos modelos de PPS III-A, III-B e III-C

Brasil - 2000

\begin{tabular}{|c|c|c|c|c|c|c|c|c|c|}
\hline \multirow{2}{*}{ Deficiências } & \multirow{2}{*}{ Categoria } & \multicolumn{4}{|c|}{ P-Valor (significância) } & \multicolumn{4}{|c|}{ Coeficiente } \\
\hline & & Atendimento & $e_{0}$ & $\mathbf{e}_{4}$ & $e_{8}$ & Atendimento & $e_{0}$ & $\mathbf{e}_{4}$ & $e_{8}$ \\
\hline Mental & Deficiente & 0,000 & 0,000 & 0,000 & 0,000 & $-1,78$ & $-2,57$ & $-0,13$ & 0,41 \\
\hline \multirow[t]{4}{*}{ Enxergar } & & 0,000 & 0,000 & 0,000 & 0,019 & & & & \\
\hline & Incapaz & 0,000 & 0,000 & 0,083 & 0,640 & $-2,33$ & $-2,67$ & $-0,45$ & $-0,21$ \\
\hline & Grande dificuldade & 0,000 & 0,000 & 0,000 & 0,755 & $-0,28$ & $-0,39$ & $-0,28$ & $-0,02$ \\
\hline & Alguma dificuldade & 0,000 & 0,000 & 0,000 & 0,002 & 0,14 & 0,08 & $-0,08$ & $-0,06$ \\
\hline \multirow[t]{4}{*}{ Ouvir } & & 0,000 & 0,000 & 0,000 & 0,061 & & & & \\
\hline & Incapaz & 0,000 & 0,000 & 0,000 & 0,046 & $-1,31$ & $-2,33$ & $-0,89$ & 0,55 \\
\hline & Grande dificuldade & 0,000 & 0,000 & 0,000 & 0,775 & $-0,45$ & $-0,98$ & $-0,61$ & 0,04 \\
\hline & Alguma dificuldade & 0,000 & 0,000 & 0,000 & 0,070 & $-0,13$ & $-0,27$ & $-0,22$ & $-0,09$ \\
\hline \multirow[t]{5}{*}{ Físicas } & & 0,000 & 0,000 & 0,000 & 0,209 & & & & \\
\hline & Paralisia total & 0,000 & 0,000 & 0,406 & 0,377 & $-3,52$ & $-3,61$ & 0,23 & $-0,37$ \\
\hline & Paralisia das pernas & 0,000 & 0,000 & 0,000 & 0,413 & $-1,77$ & $-1,94$ & $-0,38$ & $-0,19$ \\
\hline & Paralisia de um lado & 0,000 & 0,000 & 0,000 & 0,140 & $-0,72$ & $-1,21$ & $-0,45$ & $-0,28$ \\
\hline & Falta de membro & 0,016 & 0,094 & 0,098 & 0,131 & $-0,11$ & $-0,09$ & $-0,10$ & $-0,18$ \\
\hline
\end{tabular}

Fonte: IBGE. Censo Demográfico 2000.

que mais reduzem o atendimento e $e_{0}$ são aquelas que têm menor significância em $e_{4}$, ao passo que as dificuldades de enxergar, assim como a hemiplegia e a paraplegia são ainda fortemente significativas em $e_{4}$. Essa dinâmica sugere presença de seletividade. Já a configuração das categorias de autoavaliação do ouvir, seguindo o mesmo critério, não permite inferir ocorrência de seletividade com clareza, uma vez que as categorias perdem significância conjuntamente em $e_{8}$ em ordem que difere da "gravidade" da deficiência.

A significância não é a única maneira de verificar a presença de seletividade. Pode-se afirmar que há seletividade à medida que a deficiência impactaria de forma menos incisiva para aqueles que progridem na escola a cada etapa desse processo. Sob tal perspectiva, a seletividade seria atestada também nos coeficientes, cujos valores indicariam presença de seletividade, à medida que se aproximassem de zero com o avanço na carreira escolar. Se adotado esse critério e considerados na análise somente os parâmetros com valores de $\mathrm{P}$ inferiores a 0,05 , é constatada a presença de seletividade sobre os deficientes, com exceção daqueles que declaram falta de membro (por seus parâmetros não significativos).

No quadro geral, as deficiências causam menor impacto na progressão escolar à medida que os indivíduos avançam nos anos de estudo conquistados. Considerando uma medida seletiva por definição, como a PPS, pode-se afirmar que, para os deficientes, quanto maior o número de anos de estudos adquiridos, menor é a importância da deficiência para se adquirir mais um ano de estudo. Portanto, mesmo se as barreiras sociais restritivas à escolarização se mantiverem constantes ao longo de toda a carreira escolar no ensino fundamental, a capacidade dos indivíduos de superar tais adversidades é crescente com os anos de estudo.

\section{Conclusões e contributos}

Segundo os dados do Censo Demográfico de 2000, as condições de saúde declaradas demonstram grande disparidade em sua implicação sobre os resultados 
educacionais. Todavia, tamanha diversidade encontra unidade em duas questões: indivíduos classificados em todas as categorias de deficiência conseguiram se fazer presentes na escola e nos diferentes pontos do ensino fundamental, mesmo que, em alguns casos, isso ocorra em taxas muito baixas; toda deficiência traz consigo adversidade à escolarização, seja no atendimento seja no desenvolvimento da trajetória escolar. Tais adversidades, por sua vez, tendem a se reduzir com o avanço na carreira escolar, por seleção e superação dos indivíduos.

A paralisia total (também notada por tetraplegia ou quadriplégico) compartilha com a deficiência mental e a cegueira os mais baixos coeficientes na determinação do atendimento. A paraplegia compartilha com essas duas últimas condições outro importante resultado: as três apresentam forte variação na presença de controle socioeconômico na determinação do atraso escolar. Essa constatação sugere que há grande colaboração ou dependência do contexto familiar, domiciliar e local para o desenvolvimento adequado da carreira escolar desses alunos.

As categorias de dificuldades permanentes das variáveis de capacidade funcional em enxergar e ouvir, em especial as não graves, possuem comportamentos próximos em relação aos parâmetros educacionais estudados, de modo geral implicando baixa interferência e significância sobre esses. Outro elemento interessante é sua associação com fatores socioeconômicos, desfavorecedores aos resultados educacionais esperados, desde sua definição (uma vez que a utilização de facilitadores como óculos e aparelhos auditivos deve ser considerada na investigação do quesito) e clarificados pelos resultados. Potencialmente, políticas de saúde e economia da família poderiam mais facilmente tratar as desvantagens enfrentadas por quem vive com tais condições de saúde, por meio da provisão de mecanismos facilitadores que atuem sobre as capacidades individuais. Faz-se importante ressaltar que os resultados assinalam que a escola pode ter um papel relevante na identificação das dificuldades não graves, especialmente quanto à capacidade de enxergar.
A hemiplegia e a paraplegia obtiveram resultados próximos, sendo a segunda condição a causadora de maior desvantagem na educação, como em sua alta implicação sobre o atendimento. Essas deficiências, assim como a grande dificuldade em ouvir, formam um conjunto de sólidos resultados intermediários entre as deficiências mais e menos restritivas, que não devem ser ignoradas. Por outro lado, a falta de membro (perna, braço, mão, pé ou dedo polegar) está relacionada a resultados de baixa interferência e significância.

No que tange à intervenção dos fatores de natureza socioeconômica, nota-se facilmente que, em linhas gerais, os elementos utilizados na delimitação do contexto pouco interferem no impacto das deficiências sobre o atendimento, ao passo que no atraso escolar possuem grande implicação.

Este estudo sugere que as principais barreiras para o desenvolvimento da educação dos deficientes, especialmente os menos atendidos, se encontram na entrada/ permanência na escola, indicadas pela importância da conclusão com sucesso do primeiro ano de estudo, no qual as deficiências indicam ser mais determinantes. Portanto, é principalmente sobre a promoção do ingresso - a adaptação à (e da) escola - que se recomendam ações do Estado para a garantia do direito à educação e à educação especial. Por outro lado, para as condições que se demonstraram mais restritivas ao atendimento, é inegável a importância do contexto familiar para o sucesso na inserção dos indivíduos. Desta forma, medidas de empoderamento familiar, em especial no que diz respeito ao poder econômico, teriam em potencial a capacidade de promover a escolarização desses grupos populacionais. Formular políticas que agiriam no sentido de garantir a educação dos menos atendidos pode representar um desafio a um Estado que restringe ao âmbito escolar as ações de desenvolvimento da educação especial.

Ainda falta informação para se entender por qual meio a dinâmica populacional da última década e os caminhos percorridos pela educação influenciaram a escolarização dos deficientes. No entanto, ao monitorar 
as matrículas de pessoas com deficiência entre 1998 e 2006, o Ministério da Educação (2008) demonstra que fortes mudanças vêm ocorrendo ao longo do tempo. O aumento do atendimento escolar (de 107\% nas matrículas ao longo deste período), promovido principalmente pela crescente inserção de deficientes em escolas regulares e classes comuns (aumento de $640 \%$ no mesmo período), corrobora para uma forte mudança no cenário da educação dos deficientes. Certamente, esse panorama indica a formação de uma nova demanda educacional, contudo, avaliações internas da educação, ou seja, aquelas decorrentes de dados escolares não são suficientes

\section{Referências}

ARANHA, M. Paradigmas da relação da sociedade com as pessoas com deficiência. Revista do Ministério Público do Trabalho, Brasília, ano 11, n. 21, p. 160-173, mar. 2001.

BECKER, G. Human capital: a theorical and empirical analisys, with special reference to education. Chicago: University of Chicago Press, 1964.

COLEMAN, J. Desempenho nas escolas públicas (extraído de 1966). In: BROOKE, N.; SOARES, J. (Orgs.). Pesquisa em eficácia escolar: origem e trajetórias. Belo Horizonte: Editora UFMG, 2008.

DINIZ, D. O que é deficiência. São Paulo: Brasiliense, 2007(Coleção Primeiros Passos, v. 324).

FRANÇA, T. Deficiência e escolarização no Brasil: um estudo acerca do atendimento, atraso e progressão escolar dos deficientes segundo o Censo 2000. Dissertação (Mestrado em Demografia) - Centro de Desenvolvimento e Planejamento Regional, Universidade de Minas Gerais, Belo Horizonte, 2010.

GUIMARAES, R. Desigualdade de oportunidades educacionais: seletividade e progressão por série no Brasil, 1986 a 2008. In: GUIMARAES, R. Probabilidade de progressão por série no Brasil: evolução, se- para a delimitação global do problema do atendimento e progressão escolar. Recomenda-se, portanto, a manutenção da investigação da educação também por avaliações externas, como a presente neste estudo, de modo a complementar o conhecimento sobre o quadro geral da educação das pessoas com deficiência, incluindo também aqueles que estão fora da escola e os demais fatores sociais envolvidos nessa dinâmica.

Nos próximos anos, é esperado que, por meio dos dados do Censo Demográfico de 2010, estas questões possam ser revisitadas e atualizadas, tendo como suporte os resultados aqui expostos.

letividade e aplicação de modelos de idade-período-coorte. Dissertação (Mestrado em Demografia) - Centro de Desenvolvimento e Planejamento Regional, Universidade de Minas Gerais, Belo Horizonte, 2010.

HANUSHEK, E. Publicy provided education. In: AUERBACH, A.; FELDSTEIN, M. Handbook of public economics. Amsterdam: Elsevier Science, v. 4, 2002.

HOSMER, D.; LEMESHOW, S. Applied logistic regression. New York: J. Wiley, 1989.

IBGE. Manual do recenseador censo 2000. Rio de Janeiro, 2000.

LANNA JR., M. História do movimento político das pessoas com deficiência no Brasil. Brasília: Secretaria de Direitos Humanos, Secretaria Nacional de Promoção dos Direitos da Pessoa com Deficiência, 2010.

MACEDO, G. Fatores associados ao rendimento escolar de alunos da $5^{a}$ série (2000) - uma abordagem do valor adicionado. In: XIV ENCONTRO NACIONAL DE ESTUDOS POPULACIONAIS. Anais... Caxambu, Abep, 2004.

MARE, R. Social background composition and educational growth. Demography, Chicago, v. 16, n. 1, p. 55-71, Feb.1979. 
Social background and school continuation decisions. Journal of the American Statistical Association, New York, v. 75, n. 370, p. 295-305, June 1980.

. Change ans stability in educational stratification. American Sociological Review, Menasha, v. 46, n. 1, p. 72-87, Feb. 1981.

MEC - Ministério da Educação. Política nacional de educação especial na perspectiva da educação inclusiva. Brasília, 2008.

MONT, D. Measuring disability prevalence. Washington: World Bank, 2007 (Social Protection Discussion Paper Series, 0706).

NERI, M. et al. Retratos da deficiência no Brasil. Rio de Janeiro: FGV/lbre, CPS, 2003.

RIANI, J.; GOLGHER, A. Indicadores educacionais confeccionados a partir de bases de dados do IBGE. In: RIOS-NETO, E.; RIANI, J. (Orgs.). Introdução à demografia de educação. Campinas: Abep, 2004. p.89-128.
RIOS-NETO, E. O método probabilidade de progressão por série. In: RIOS-NETO, E.; RIANI, J. (Orgs.). Introdução à demografia de educação. Campinas: Abep, 2004, p.145-158.

TODD, P.; WOLPIN, K. On the especification and estimation of the production function for cognitive achievement. The Economic Journal, Cambridge, v. 113, n. 481, p. F3F33, Feb. 2003.

UNESCO. Relatório de monitoramento de educação para todos: educação para todos em 2015, alcançaremos a meta? Brasília, 2008.

UPIAS - The Union of the Physically Impaired Against Segregation. Fundamental principles of disability. [1975?]. Disponível em: <http://www.leeds.ac.uk/disabilitystudies/archiveuk/UPIAS/fundamental\%20 principles.pdf > . Acesso em: 20 ago. 2009.

\section{Resumen}

La escolarización de personas con discapacidad en Brasil: atención, atraso y progresión en la enseñanza fundamental según el Censo 2000

El presente artículo tiene como objetivo poner en evidencia la implicación de las diferentes discapacidades en áreas como la atención, el atraso y la progresión escolar en la enseñanza fundamental. Para ello, se utiliza el modelo estadístico logístico binario. Tras la presentación de los diferentes conceptos de discapacidad, usando como instrumento el Censo 2000, transcurre el análisis de las áreas mencionadas anteriormente. La progresión escolar se investiga por medio de una medida denominada Probabilidad de Progresión por Clase ${ }^{11}$ (PPS), tratándose, además, de uno de los tres puntos de mayor relevancia en el desarrollo de la enseñanza fundamental. Los resultados indican una gran disparidad entre las discapacidades en la determinación de los elementos investigados. En general, todas las condiciones se muestran como factores que desfavorecen el desarrollo en la carrera escolar. Sin embargo, la implicación de las discapacidades sobre la PPS se reduce con el avance en la enseñanza fundamental, siendo también menos significativa en cada una de las etapas siguientes. Entre los ámbitos analizados, el atraso escolar demostró sufrir una relevante variación, debido al control por factores de naturaleza socioeconómica. En lo restante, este trabajo contiene resultados y contribuye al desarrollo científico de esta área de estudio.

Palabras-clave: Discapacidad. Atención escolar. Atraso escolar. Probabilidad de progresión por clase.

\footnotetext{
11 Nota libre del traductor: las siglas PPS (Probabilidade de Progressão por Série) han sido traducidas por Probabilidad de Progresión por Clase.
} 


\begin{abstract}
The schooling of disabled people in Brazil: attendance, retention and progression in primary education according to the 2000 Census

This article aims to highlight the implications of disabilities in attendance, retention and progression in primary schools, using binary logistic statistical modeling. After presenting the different concepts of disability using the 2000 Census, we analyze the following questions. School progression is investigated using a measure called Grade Progression Probability (GPP), with the three most relevant points in the development of basic education. The results show wide disparity disabilities in determining the elements investigated. In general, all conditions are factors discouraging development in the school life. However, the implication of disabilities on the GPP decreases with each grade in elementary school, being less significant at each subsequent grade. Among the issues we analyzed, grade retention demonstrated a more significant variation, given the nature of controlling socioeconomic factors. Moreover, this study contains results and points to contributions to the scientific development of this area.
\end{abstract}

Keywords: Disability. School attendance. Grade retention. Grade progression probability.

Recebido para publicação em 04/11/2011

Aceito para publicação em 09/03/2012 
Anexo I

Modelos estimados

\begin{tabular}{|c|c|c|c|}
\hline $\begin{array}{l}\text { Nome do } \\
\text { modelo }\end{array}$ & Variável resposta & Variáveis explicativas & $\begin{array}{l}\text { Filtro de } \\
\text { frequência à } \\
\text { escola }\end{array}$ \\
\hline I-A & & $\begin{array}{l}\text { Idade, sexo, problema mental permanente, capacidade de } \\
\text { enxergar, capacidade de ouvir e paralisias (e falta de membro). }\end{array}$ & - \\
\hline I-B & Atendimento & $\begin{array}{l}\text { Idade, sexo, problema mental permanente, capacidade de } \\
\text { enxergar, capacidade de ouvir, paralisias (e falta de membro), } \\
\text { cor, família mononuclear (ou não), localização domiciliar (rural } \\
\text { ou urbano), região geográfica, área metropolitana (ou não), } \\
\text { água encanada, esgoto, eletricidade, coleta de lixo, presença } \\
\text { de microcomputador, anos de estudo do chefe da família e } \\
\text { densidade de moradores por dormitório. }\end{array}$ & - \\
\hline II-A & & $\begin{array}{l}\text { Idade, sexo e problema mental permanente, capacidade de } \\
\text { enxergar, capacidade de ouvir, paralisias (e falta de membro). }\end{array}$ & Ativo \\
\hline II-B & Atraso & $\begin{array}{l}\text { Idade, sexo, problema mental permanente, capacidade de } \\
\text { enxergar, capacidade de ouvir, paralisias (e falta de membro), } \\
\text { cor, família mononuclear (ou não), localização domiciliar (rural } \\
\text { ou urbano), região geográfica, área metropolitana (ou não), } \\
\text { água encanada, esgoto, eletricidade, coleta de lixo, presença } \\
\text { de microcomputador, anos de estudo do chefe da família e } \\
\text { densidade de moradores por dormitório. }\end{array}$ & Ativo \\
\hline III-A & $e_{0}$ & $\begin{array}{l}\text { Idade, sexo, problema mental permanente, capacidade de } \\
\text { enxergar, capacidade de ouvir, paralisias (e falta de membro), } \\
\text { cor, família mononuclear (ou não), localização domiciliar (rural } \\
\text { ou urbano), região geográfica, área metropolitana (ou não), } \\
\text { água encanada, esgoto, eletricidade, coleta de lixo, presença } \\
\text { de microcomputador, anos de estudo do chefe da família e } \\
\text { densidade de moradores por dormitório. }\end{array}$ & - \\
\hline III-B & $e_{4}$ & $\begin{array}{l}\text { Idade, sexo, problema mental permanente, capacidade de } \\
\text { enxergar, capacidade de ouvir, paralisias (e falta de membro), } \\
\text { cor, família mononuclear (ou não), localização domiciliar (rural } \\
\text { ou urbano), região geográfica, área metropolitana (ou não), } \\
\text { água encanada, esgoto, eletricidade, coleta de lixo, presença } \\
\text { de microcomputador, anos de estudo do chefe da família e } \\
\text { densidade de moradores por dormitório. }\end{array}$ & - \\
\hline III-C & $e_{8}$ & $\begin{array}{l}\text { Idade, sexo, problema mental permanente, capacidade de } \\
\text { enxergar, capacidade de ouvir, paralisias (e falta de membro), } \\
\text { cor, família mononuclear (ou não), localização domiciliar (rural } \\
\text { ou urbano), região geográfica, área metropolitana (ou não), } \\
\text { água encanada, esgoto, eletricidade, coleta de lixo, presença } \\
\text { de microcomputador, anos de estudo do chefe da família e } \\
\text { densidade de moradores por dormitório. }\end{array}$ & - \\
\hline
\end{tabular}




\begin{tabular}{|c|c|c|c|c|c|}
\hline \multicolumn{6}{|c|}{$\begin{array}{c}\text { Anexo II } \\
\text { Valores das PPS, } e_{0}, e_{4} \text { e e } 8 \\
\text { Brasil }-2000\end{array}$} \\
\hline \multirow[t]{2}{*}{ Deficiências } & Categorias & $e_{0}$ & $e_{4}$ & $e_{8}$ & $e_{0} . e_{4} . e 8$ \\
\hline & Geral & 83,9 & 75,8 & 54,9 & 34,9 \\
\hline Mental & Deficiente & 49,5 & 76,3 & 74 & 27,9 \\
\hline \multirow[t]{3}{*}{ Enxergar } & Incapaz & 24,2 & 77,9 & 80 & 15,1 \\
\hline & Grande dificuldade & 76,2 & 72,1 & 59,5 & 32,7 \\
\hline & Alguma dificuldade & 86,5 & 74,3 & 55,2 & 35,5 \\
\hline \multirow[t]{3}{*}{ Ouvir } & Incapaz & 42,5 & 69,9 & 83,5 & 24,8 \\
\hline & Grande dificuldade & 62,6 & 67,3 & 69,1 & 29,1 \\
\hline & Alguma dificuldade & 77,8 & 70,8 & 55,8 & 30,7 \\
\hline \multirow[t]{4}{*}{ Físicas } & Paralisia total & 10,7 & 85 & 80,2 & 7,3 \\
\hline & Paralisia das pernas & 40 & 72,7 & 73,2 & 21,3 \\
\hline & Paralisia de um lado & 54,4 & 72 & 66,4 & 26,0 \\
\hline & Falta de membro & 82,6 & 74,3 & 52,4 & 32,2 \\
\hline
\end{tabular}

Fonte: IBGE. Censo Demográfico 2000. 
